\title{
Toward an action-based view of dynamic capabilities for international business
}

\author{
Shaker A. Zahra ${ }^{1}$, \\ Olga Petricevic ${ }^{2}$ and \\ Yadong Luo $^{3}$
}

${ }^{1}$ Robert E. Buuck Chair of Entrepreneurship, Academic Director of The Gary S. Holmes Center For Entrepreneurship, Strategic Management \& Entrepreneurship Department, Carlson School of Management, University of Minnesota, Minneapolis, MN 55455, USA; ${ }^{2}$ Strategy and Global Management Area \& Entrepreneurship and Innovation Area, Haskayne School of Business, University of Calgary, Calgary, AB T2N 1N4, Canada; ${ }^{3}$ Emery M. Findley, Jr. Distinguished Chair and Professor of Management, Department of Management, Miami Herbert Business School, University of Miami, Coral Gables, FL 33146, USA

Correspondence:

O Petricevic, Strategy and Global

Management Area \& Entrepreneurship and Innovation Area, Haskayne School of Business, University of Calgary, Calgary, AB T2N 1N4, Canada

e-mail: o.petricevic@haskayne.ucalgary.ca

\begin{abstract}
A growing body of research highlights the importance and development of dynamic capabilities as well as the contingencies that can affect such development. However, existing research pays limited attention to the demands of competition in today's dynamic, volatile, and ambiguous international markets. The international business (IB) realities and contexts require companies to develop and effectively deploy dynamic capabilities to achieve evolutionary fitness, adapt, and successfully exploit opportunities (and neutralize threats) stemming from technological, social, geopolitical, institutional, and economic changes and interdependencies among various layers of embeddedness. Consequently, in this article, we discuss dynamic capabilities that tailor to the specifics of IB contexts, underscore their conceptual properties relevant for the IB realities, and articulate the processes involved in their building and leveraging by established and young MNEs. We further clarify the entrepreneurial foundations and actions essential for development and effective deployment of dynamic capabilities for IB. Finally, we offer our suggestions on how future IB research should explore these issues so as to make dynamic capabilities thinking actionable.
\end{abstract}

Journal of International Business Studies (2022) 53, 583-600.

https://doi.org/I0.1057/s41267-021-00487-2

Keywords: dynamic capabilities; international business; multinational enterprises (MNEs); international new ventures (INVs); emerging-market MNEs; de-globalization; action-based view

\section{INTRODUCTION}

Dynamic capabilities (DCs) are important for ensuring organizational adaptation and sustainable growth in complex and changing environments (Helfat, Finkelstein, Mitchell, Peteraf, Singh, Teece, \& Winter, 2007; Teece, Pisano, \& Shuen, 1997; Zahra, Sapienza, \& Davidsson, 2006; Zollo \& Winter, 2002). They are especially relevant for multinational enterprises (MNEs) and other companies that operate across international borders (Pitelis \& Teece, 2010; Teece, 2014). The constantly changing international business (IB) landscape demands effective and agile cross-border orchestration, integration, renewal, reconfiguration, and upgrading of critical resource bundles including the routines and capabilities vital for organizational success (Luo, 2000, 2002; Matysiak, Rugman, \& Bausch, 2018). The recent shifts in the global economic landscape, the rise of neo techno-nationalism coupled with uncertainty and
Received: 23 November 2020

Revised: 21 April 2021

Accepted: 12 July 2021

Online publication date: 3 February 2022 
complexity of de-globalization have made it essential for companies competing internationally to effectively develop, hone, and deploy sophisticated DCs to achieve evolutionary fitness (Petricevic \& Teece, 2019; Zahra, 2020).

To date, research on DCs has primarily been conducted in the strategic management field, often overlooking the challenges and opportunities created by the uniqueness, richness and dynamics of IB contexts. Recognizing and understanding these contexts could both enrich our appreciation of DCs and reveal relevant boundary conditions and working processes. While research in IB offers some preliminary insights into the role of DCs in identifying and explaining the antecedents, processes, and consequences of cross-national business activities of MNEs, and to some extent emerging-market MNEs (EMNEs) (e.g., Al-Aali \& Teece, 2014; Augier \& Teece, 2007; Deng, Liu, Gallagher, \& Wu, 2020; Lessard, Teece, \& Heaton, 2016a; Luo, 2000; Pitelis \& Teece, 2010; Sapienza, Autio, George, \& Zahra, 2006; Teece, 2014; Weerawardena, Mort, Liesch, \& Knight, 2007), these efforts have largely remained at the conceptual level. These efforts have primarily sought to illustrate the relevance of DCs for MNEs while offering little insight into how to make these capabilities actionable to gain strategic leverage and competitive advantage in today's international markets and to support growth trajectories of these firms.

In this article, we focus on how to make DCs actionable for MNEs, whether young or established. Towards this end, we advance an action-based view that highlights the role of executives and entrepreneurs in developing and effectively deploying a set of DCs to achieve success in international markets. We propose that making these capabilities actionable requires attention to their underlying processes, entrepreneurial foundations, and unique conducts (business activities) that are effective in addressing new IB realities. These dynamics are likely to vary considerably across different types of international firms but are, in large part, shaped by managerial actions and have the potential to shape the contexts in which these firms operate. Moreover, our discussion highlights the rich interplay between unique conceptual properties of dynamic capability development in IB and the important actions imperative for MNEs to gain advantage in the contemporary international marketplace.

\section{CONCEPTUALIZING DYNAMIC CAPABILITIES IN IB}

\section{The Literature Landscape: Dynamic Capabilities and IB}

In order to better understand the literature landscape on DCs, and appreciate its relevance for IB, we conducted a scoping search using the Web of Science database. We searched for the number of publications where the word "dynamic" occurs within one word from various forms of the word "capability." Our search covered the 1997-2020 period (year 1997 marking the seminal publication on DCs by Teece et al., 1997). We then expanded our search using the list of IB-specific terms. Figure 1 illustrates an exponential growth of studies on DCs and a disproportionately low growth rate of studies on DCs in IB during the same period. When looking specifically at the journal outlets where work on DCs and IB during the same 1997-2020 period was published, we noted that those publications were mainly concentrated in few IB-specific journals. The results of our literature review highlight both the scarcity and narrow reach of studies that have integrated the dynamic capability thinking and IB-related topics.

Next, we looked at the conceptual and empirical studies that have examined DCs in international settings. To ensure clarity, we have separated studies that examined born global ventures and international new ventures (INVs) in one group and those that examined established companies such as MNEs, EMNEs and small and medium-size business firms in another group. This tabulation further highlighted the dearth of studies both conceptual and empirical on DCs in entrepreneurial firms (born global and INVs) specifically. One possible explanation is that earlier research on DCs has primarily focused on large and established companies, as they usually command considerable resources and experiences that are seen as necessary to undertake large-scale reconfiguration, bundling, and upgrading processes associated with building and maintaining the currency of DCs. Thus, we found that existing research on DCs in IB places greater attention on studying DCs in those international settings where established companies compete (e.g., Cui \& Jiao, 2011; Fang \& Zou, 2009; Parente, Baack, \& Hahn, 2011; Wu, Chen, $\&$ Jiao, 2016).

Despite the strong conceptual link between DC thinking and IB research questions (Dunning \& 


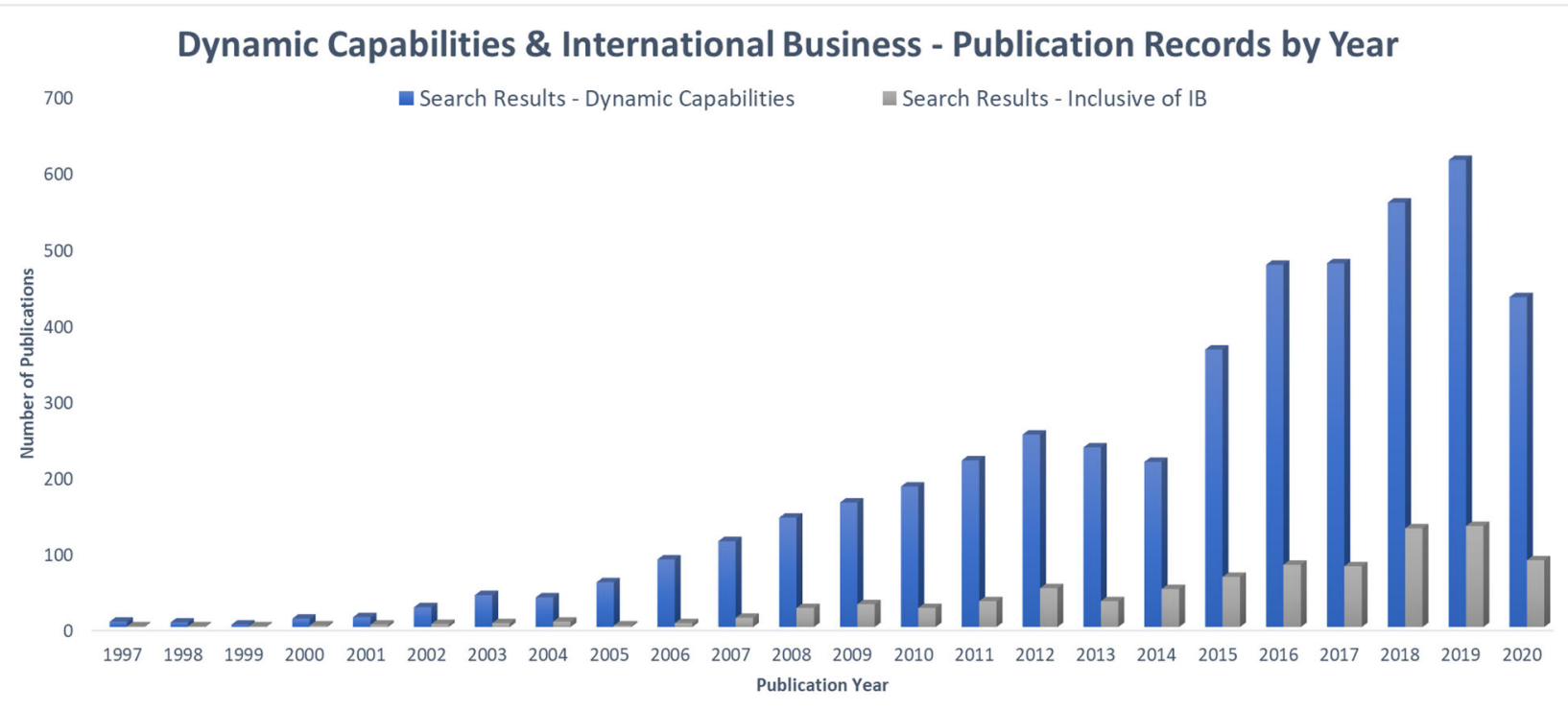

Figure 1 Literature integration of dynamic capabilities in IB (1997-2020).

Lundan, 2010; Matysiak et al., 2018; Teece \& Petricevic, 2020), research on DCs in IB remains limited and fragmented. Further, our evaluation of prior studies reveals five shortcomings of research integrating DCs and IB. First, prior studies define DCs differently, making it difficult to compare and contrast findings and draw generalizations. Second, the few empirical studies carried out to date have not been systematic in operationally measuring DCs. In particular, there is a paucity of strong, nuanced, and actionable empirical studies that focus on applying, extending, and testing the DC construct and its constituent elements in the IB context. As a result, we know little about the types of these DCs and even less about their different dimensions. Similarly, little empirical research exists today on the process of capability reconfiguration intended to address the competing mandates of local adaptation and cross-border reach that are critical for IB. Third, the IB contexts in which these studies were done vary considerably, making it difficult to appreciate the conditions under which companies gain value from deploying or reconfiguring their DCs. Thus, the extent and sources of the differences among DCs across different IB contexts are not well understood. Fourth, limited attention has been given to the nature of DCs in new ventures in general and INVs in particular. As new types of firms (micro-MNEs, global platform complementors, springboard EMNEs, etc.) emerge in the international marketplace, it becomes essential to understand how the DCs' framework can be applied (or perhaps needs to be modified) to better understand these firms' internationalization behaviors. Fifth, prior studies collectively lack attention to ways managers operating in international markets make their companies' DCs actionable. In short, existing studies highlight the importance of DCs in international markets, revealing the diversity of views on their nature and contributions. However, they lack an actionable perspective of the role of these capabilities in IB.

Conceptualizations of Dynamic Capabilities for IB In the IB literature, the concept of DCs has been related by some to the concept of firm-specific advantages (FSAs) (Rugman \& Verbeke, $2001,2003)$. FSAs refer to the unique bundles of resources, in the form of organizational routines and capabilities, that are both dynamic in nature and can lead to evolutionary fitness (Helfat et al., 2007; Narula \& Verbeke, 2015). As Rugman, Verbeke, and Nguyen (2011) observe, recent IB research has moved towards a more nuanced understanding of the manner in which MNEs in home and host countries interact to develop novel recombinations of country-specific advantages (CSAs) and the FSAs held by their internationally dispersed units. Several scholars have also noted that DC thinking can lead to effective approaches for studying the nature, the role, and the effects of 
future-oriented endowments of resource bundles and related FSAs - in explaining IB processes and outcomes (Augier \& Teece, 2007; Peng, 2001; Teece, 2014).

Existing studies also suggest that MNEs transfer productive knowledge across borders through internalization (e.g., wholly owned or joint venture investment) because the market system (e.g., licensing) fails to trade such knowledge (Hennart, 1982), and because the MNE itself is a social community that creates and internally transfers such knowledge (Kogut \& Zander, 1992). Hence, internalization enables resource deployment and knowledge transfer within a cross-border integrated organizational system. In this context, DCs facilitate resource deployment and alignment (evolutionary fitness) with the environmental dynamics of a host country and the organizational needs of the MNE's network. Absent such an alignment, economic returns from these resources could decrease while the risks associated with unintentional misappropriation of knowledge and intellectual property (IP) may increase (Inkpen, Minbaeva, \& Tsang, 2019). Adopting a DC perspective can sharpen the MNE's overall vision toward knowledge improvement and resource deployment that captures both local adaptation and cross-border integration (Luo, 2000).

More recently, some researchers have suggested that DCs' framework provides a starting point to identify specific activities and processes that facilitate MNEs' growth in host markets that are structurally, institutionally, geopolitically, and culturally different and continuously evolving (Lundan \& Li, 2019; Petricevic \& Teece, 2019; Teece \& Petricevic, 2020). In this spirit, there is agreement that IB theory and research can be greatly enriched by pushing forward numerous issues that are specific to different types of MNEs and INVs through an interdisciplinary lens (Cheng, Birkinshaw, Lessard, \& Thomas, 2014). Specifically, unveiling actionable insights into DC development and deployment can highlight how internationally operating firms can achieve value creation through evolutionary fitness with host environments. Some of the activities concern network optimization and governance of global value chains (GVCs), where MNEs orchestrate networks of chain participants and multiplexity of relationships (Pananond, Gereffi, \& Pedersen, 2020). Some other activities concern MNEs' subunits agency in responding to host institutional environments by actively innovating around institutions as opposed to passive counteraction (Regnér \& Edman, 2014). The DC framework can accommodate both the requisite orchestration activities as well as help shape some of the institutional environments in which MNEs compete, among other activities (Teece, 2014). The richness of the IB contexts can help researchers explicate a more nuanced understanding of capacities underpinning DCs and the mechanisms that enable their effective development and deployment, thus making them actionable.

When applied to IB, the dynamic capability perspective complements the premise of resourcebased view (RBV) thinking in general (Barney, 1991) and the notion of FSA or ownership advantages in particular (Rugman, 1981). However, it contrasts with the economic-based, foundational views that have shaped much of the leading IB theories and frameworks in regards to the nature of economic rents that the firm is expected to generate. The DCs perspective assumes, but goes beyond, the premise of owning and controlling superior assets and resources or efficiency-seeking objectives. Instead, the premise of DCs perspective with its interdisciplinary roots, evolutionary and process-oriented approaches (and more recently, a configurational approach) is on achieving evolutionary fitness between the MNE and its external environment (Teece, 2014, 2018; Wilden, Devinney, \& Dowling, 2016). Thus, rents are generated from those actions rooted in organizational adaptation, learning, entrepreneurial behaviors, managerial intention, organizational heritage, and signature processes in purposefully reconfiguring and upgrading MNE's resource and routine reservoirs and assets (within and across enterprise boundaries) to position it to effectively to respond to a rapidly shifting environment, and to some extent, shape its environment.

Scholars have identified three essential clusters of activities that enable emergence of DCs, particularly: (1) sensing opportunities and threats, (2) seizing (and neutralizing) them, and (3) reconfiguring organizational processes, assets and routines (Teece, 2007). Applying this thinking to the MNE, Teece (2014: 18) specifically highlights: (1) identification and assessment of opportunities at home and abroad; (2) mobilization of resources globally to address opportunities, and to capture value from doing so; and (3) continued renewal. The role of signature processes and business models, rooted in the MNE's organizational heritage and supported by organizational history, experience, culture and creativity underpin the process of dynamic capability development and deployment in IB contexts. 
Building on the existing research on DCs (Luo, 2000; Teece, 2007, 2014; Teece et al., 1997) and FSAs and CSAs in IB (Rugman \& Verbeke, 2001, 2003), we define a dynamic capability for IB as the firm's ability to effectively and continuously build, bundle, mobilize, integrate, reconfigure, upgrade and protect critical resources, so as to address rapidly changing environments in geographically dispersed, yet internationally coordinated markets in which it competes. Our definition is consistent with the "new" internalization theory, emphasizing shifts towards the recombination, or bundling of existing FSAs with CSAs available in a host country (Hennart, 2009; Verbeke, 2009). It is also consistent with the emerging views of the MNE, that conceptualize it as the 'meta-integrator' that seeks to orchestrate the global process of value creation and capture at home and across borders (Narula, 2017; Pitelis \& Teece, 2018). Indeed, Narula and Verbeke (2015) have suggested that developments in the internalization theory anticipated the DCs' approach as it predicted that successful MNEs (including entrepreneurial firms operating internationally) are those able to engage in systematic orchestration of firm's resource reservoirs to effectively and entrepreneurially respond to opportunities and challenges of IB environments. Thus, the definition we propose here captures the domain of DCs in IB contexts while highlighting the need for making them actionable.

\section{The conceptual properties of dynamic capabilities for IB}

A major barrier to research progress is the lack of understanding of the key properties of DCs, especially relevant within IB settings. These properties affect the conception, development, deployment, and maintenance of these capabilities in practice. They also affect the measurement and operationalization of DCs from the scholarly perspective when considering the complexity and dynamism of IB contexts. Five such properties are particularly relevant: plurality, integration, evolution, dynamism, and idiosyncrasy, as discussed next.

Plurality: IB operations demand entrepreneurial actions that allow MNEs to develop new business models, creative organizational designs and/or competitive strategies that give them advantage over other MNEs and domestic players. The need for regional, national, and subnational responsiveness usually demands creative and timely adaptation and reconfiguration (Verbeke \& Asmussen, 2016). This rests on plurality of actions that can occur at multiple levels inside an organization and a multitude of boundary-spanning interactions in an international setting, but also interactions with the broader social and political institutions and actors MNE encounters over time, including "regulators, standard-setting bodies, laws, social mores, and business ethics [...] complementors, suppliers", which can facilitate the co-evolutionary process of dynamic capability development (Teece, 2007: 1325). Consequently, many MNE activities have become more geographically dispersed and operationally disaggregated, amplifying the plurality of actions that demand effective DCs. In turn, this plurality is also reflected in the multi-dimensionality of the DCs' construct itself (Winter, 2003). As MNEs' operations span a multitude of institutional, cultural, geographic, and political environments, and engage with different sets of stakeholders, these activities demand plurality of unique bundles of FSAs, CSAs, and DCs, that need to be carefully selected, orchestrated, and deployed.

Integration: Plurality is important for addressing differences across IB contexts. However, it can result in redundancies and even inefficiency. Integration is a core function and a source of MNE's competitive advantage, allowing it to tap into and integrate organizationally and geographically dispersed pools of knowledge and resources (Kostova, Marano, \& Tallman, 2016). There are many integration mechanisms which include: centralization of decision-making, formalization and standardization of organizational processes, and socialization through shared values and common organizational cultures (Zeng, Grøgaard, \& Steel, 2018). Integration also enables the development of DCs. Early on, Iansiti and Clark (1994) found that integration of both internal and external knowledge is an important DC-building process. Furthermore, Teece (2007: 1331) suggests, "a company's integration upstream, downstream, as well as externally, is partially driven by the need to build capabilities." More recently, scholars are calling attention to the rising digitalization that redefines the nature of ownership advantages and governance choices (Banalieva \& Dhanaraj, 2019). Network-based resource bundling, integration, and reconfiguration becomes more prevalent as MNEs are required to include the digitalization-based connectivity capability into their DC building activities, aiming to better identify new business opportunities while providing new value propositions to their international customers. Digital platforms and ecosystems also embody new forms of connectivity among 
cross-border partners that in turn redefine the ways by which knowledge is sourced, transferred, transformed, and deployed. These ecosystems are characterized by modularity and loose ties, and embody more fluid and flexible forms of resource recombination and deployment. To this end, Li, Chen, Yi, Mao, and Liao (2019) propose the concept of ecosystem-specific advantage, calling for more research on the dynamic process of creating, transferring, and upgrading such advantages in the IB context. Aligned with the precepts of the ecosystems approach is the DCs' framework, most recently conceptualized as a form of an applied system of interdependent linkages (Teece, 2018), reinforcing the need for integration as a key property of DCs in IB contexts.

Evolution: The complexity of making DCs actionable also stems from the fact that novel resource bundle development, reconfiguration, and deployment are a continuous process that unfolds across multiple layers of embeddedness (Meyer, Mudambi, $\&$ Narula, 2011). It resembles what some call a selfregulating system of interdependent relationships (Teece, 2018). The DCs' framework explicitly assumes continuous evolution as it underscores the importance of change and learning over time, and demands constant calibration over time (Zollo $\&$ Winter, 2002). This ongoing cycle breeds different ideas for calibrating and upgrading existing resource bundles while spurring entrepreneurial activities that usher in new business concepts, models, and innovative strategic moves (Teece, 2012, 2016). In particular, Cantwell, Dunning and Lundan (2010) suggest that MNEs co-evolve with their institutional environments by adjusting their strategies and structures to counter uncertainty and complexity in the development of their own activities and in their external environment. MNEs (INVs included) need to build a nexus of networks with business ecosystem players vertically (e.g., international suppliers), horizontally (e.g., international competitors) or diagonally (with supporting service providers). They also make GVCs more open-ended, loosely coupled, with more partners that cooperate in dispersed value chain constellations (Kano, 2018). Hence, connectivity facilitates the sharing of resources, information, and knowledge with improved speed, precision, effectiveness, accountability, and flexibility. In turn, these forces highlight the importance of the continuing (co)evolution of DCs which my follow different and idiosyncratic paths across IB contexts.
Dynamism: The alignment between IB contexts, that are heterodox and eclectic, and the rapidly shifting IB economic landscape, require novel responses from MNEs, which in turn necessitate a high level of flexibility and adaptation. The changing IB realities and new forces shaping international competition (e.g., disruptive technologies, digitized globalization, the emergence of new players, fast market changes, successful catch-up by foreign laggards, and rising global geopolitical complexity) make cross-border resource and capability deployment, orchestration, reconfiguration, and upgrading more imperative and challenging. The technological and related institutional advancements are disrupting the landscape in which international firms operate, regardless of their age, size, industry, or degree of internationalization. These changes are unlikely to be transitory. MNEs are required to organize their operations in ways that are agile, flexible, integrated, and resilient, as they must also deal with a diversity of ecosystem participants and an intricate web of inter-firm and intra-firm linkages in the course of cultivating DCs (Luo, 2000, 2002; Teece, 2014, 2018). For example, Madhok and Osegowitsch (2000) show that technological advancement has significantly influenced the process and the speed of DC diffusion with the MNEs' network. This dynamism reinforces the plurality of capabilities. However, dynamism rests on the MNEs' integration, competence, and learning. This learning could vary in scope and outcomes as the learning contexts change. The peculiarities of the MNEs' expansive networks and contexts call for the "idiosyncrasy" of DCs.

Idiosyncrasy: To benefit from the DC thinking, MNEs need to re-think their governance structures, re-configure their value chain activities as well as their innovation networks in ways that underscore and shield from misappropriation tacit expertise and knowledge, signature processes, and business models (Verbeke \& Kenworthy, 2008). Having signature processes developed over time and supported by administrative heritage makes DCs hard for competitors to identify, observe or imitate, protecting their value-creating potential. This heritage is both transnational (to achieve requisite scale) and local (to achieve adaptation). Overall, this idiosyncrasy encourages plurality and dynamism; it also reinforces the importance of integration as an important property of DCs. 
To summarize, operating in IB settings provides richness that requires MNEs to develop DCs that exhibit plurality, dynamism, integration, evolution, and idiosyncrasy. The scholarly efforts need to highlight these dimensions in conceptualizations of DCs in IB as well as accommodate these properties in empirical studies on DCs in IB. The IB contexts give meaning and substance to DCs, keep them changing and current, thereby enabling MNEs to respond to emerging challenges. Given the interdependence of these conceptual properties, they require special skills in developing, orchestrating, and making them actionable in practice, otherwise discord may ensure stifling of MNEs' evolutionary processes. The increasing state of flux in the IB environment, such as de-globalization (Witt, 2019), increasing diversity of institutional contexts (Lundan \& Li, 2019), and intellectual property (IP) misappropriation is requiring DCs that enable MNEs to successfully navigate the rapidly changing and challenging landscape of global markets. These capabilities need to center on MNEs' ability to protect and buffer from the misappropriation hazards and leakage of their IP and critical knowledge assets, especially when orchestrating global value chains networks and digitally enabled innovation networks (Petricevic \& Teece, 2019). Actions that successfully address these complex environmental forces call for IB research to integrate dynamic capability building with global planning, local adaptation, risk control, and even corporate political strategies that are co-performed by corporate headquarters and foreign subunits in a coordinated manner. Figure 2 summarizes our integrative conceptualization of DCs in IB.

\section{ENTREPRENEURIAL ACTIONS FOR DYNAMIC CAPABILITIES}

As our earlier review of the current state of the literature of DCs in IB reveals, research on the linkage between entrepreneurship and DCs especially in international settings is sparse. The few studies that currently exist are also fragmented in their focus and contributions. These studies also pay greater attention to MNEs than INVs. This dearth of research on DCs within IB is surprising given the widespread recognition that entrepreneurial actions and entrepreneurial managers are essential to building and sustaining DCs and appropriating value from them (Teece, 2014, 2016). Entrepreneurship also makes DCs strategically valuable by conceiving novel ways to deploy them to create or exploit opportunities across international borders. It also infuses new knowledge into these capabilities, ensuring their plurality, dynamism, integration, idiosyncrasy, and evolution. Entrepreneurship also enables the morphing of these capabilities, creating new varieties or versions that are firm-specific, becoming the source of strategic advantage on a global scale.

Still, to gain the benefits just mentioned, MNEs need to develop and sustain an entrepreneurial DNA that penetrates all membranes of the organization, including globally dispersed subsidiaries, which we define as the capacity to envision where DCs can generate strategic leverage as well as how to best develop these capabilities and effectively integrate and manage them. Teece (2012, 2014, 2016) himself recognizes the critical importance of such an entrepreneurial culture highlighting three sets of capacities (i.e., sensing, seizing, and transforming), that form an ongoing cycle that makes evolutionary fitness possible. In turn, this requires attention to how MNEs make their DCs actionable through the entrepreneurial process.

\section{Making Dynamic Capabilities More Actionable through Entrepreneurial Processes}

Making dynamic capabilities actionable means making them organizationally purposeful, useful and productive. Toward this end, MNEs need to invest to keep their capabilities current and effectively deployed in pursuit of their goals, renewal, adaptation and evolutionary fit. Senior executives and middle managers have important roles in this regard. This role is manifested in their collective efforts to develop, upgrade or reconfigure effectively MNEs' resource bundles, making them strategically relevant and potent. This process evolves at different speeds and directions in different types of organizations. Similarly, capabilities grow and decay at different rates and for different reasons, highlighting the importance of managerial action to spur and direct these activities.

The literature highlights several organizational factors that could facilitate making DCs actionable in MNEs; these activities demand entrepreneurial thinking and behavior. Teece (2012) suggests that management needs to infuse an entrepreneurial culture throughout the organization. This favors young and agile MNEs in making capabilities actionable as it infuses entrepreneurial orientation (EO) into their decision-making processes. MNEs, 


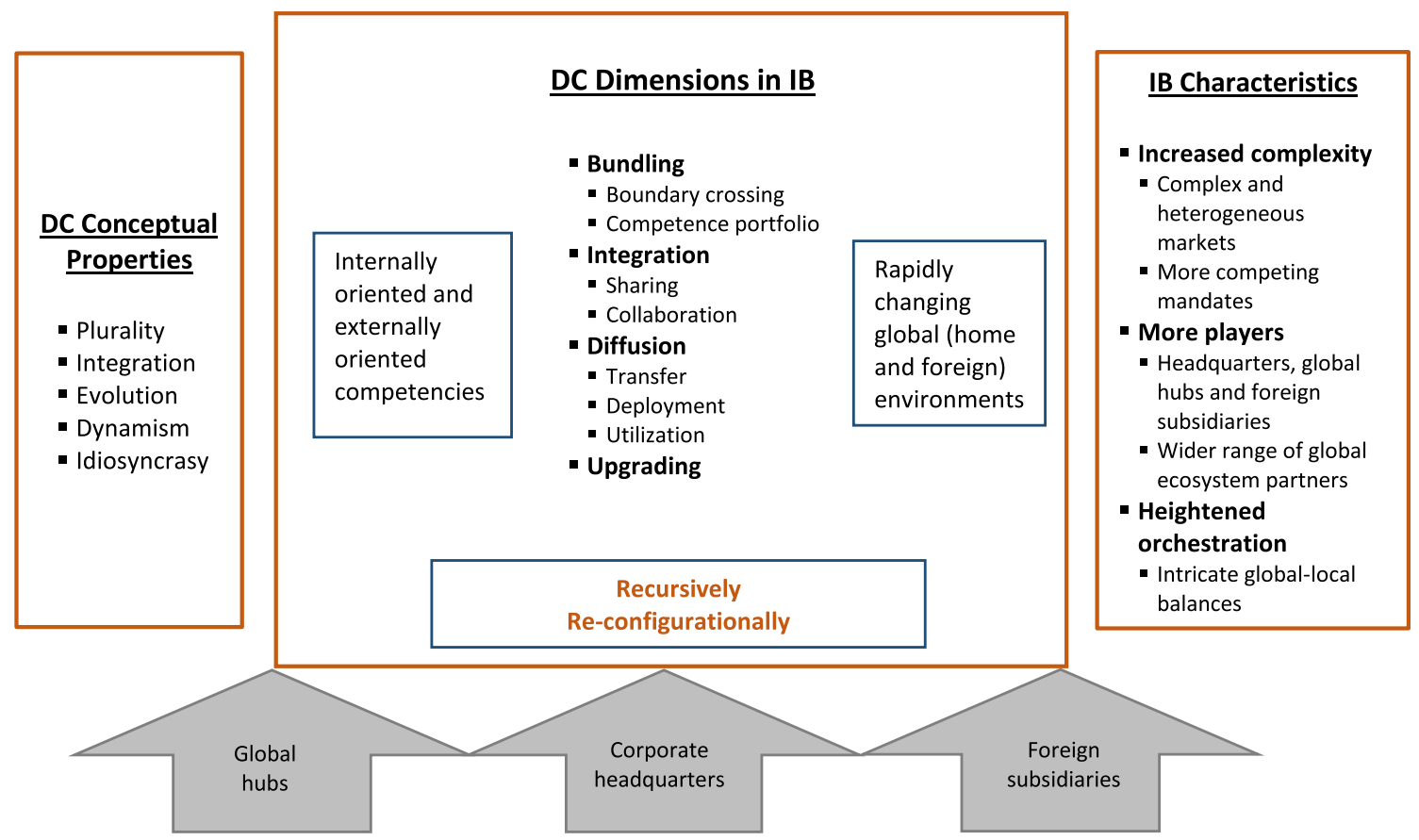

Figure 2 Conceptual properties of dynamic capabilities in international business.

while often enjoying a strong history of innovation and the presence of several dispersed capabilities, may have to work harder to promote entrepreneurial thinking and overcome inertia and managerial templates from the past. Thus, promoting EO within established hierarchies becomes an important task for MNEs' senior executives. They also need to develop systems that enable rapid knowledge sharing and communication within the MNE about DCs and their potential use. The newness of INVs could make these processes easier to navigate.

Another task centers on goal setting. MNEs' executives play an important role in setting the strategic goals for international expansion (Hutzschenreuter, Pedersen, \& Vollberda, 2007) and setting priorities that stimulate the process of capability deployment. This is followed by selecting the appropriate resource bundles and matching them to serve the different organizational objectives pursued. In turn, this enables managers operating in different parts of the organization to begin activating these capabilities (i.e., employing them in their operations). Implementation is complemented by the evaluation of effectiveness of deployment to ensure progress in achieving goals, addressing deviations, and learning from experience. Learning is important for recombining resources, and therefore also for the evolution of existing DCs and the recognition of the need for new ones (Zollo \& Winter, 2002). Entrepreneurial activities provide a key source of knowledge that allows MNEs to develop and introduce innovative business models that alter their industries' dynamics. They are also crucial for conceiving new ways to organize MNEs' operations, giving their units the flexibility and discretion they need to thrive, further fueling entrepreneurial activities. Though some of these activities are centralized, they also flourish throughout MNEs because of the autonomous actions of their subsidiaries' managers and employees (Birkinshaw, 2000; Mahnke, Venzin, \& Zahra, 2007). Yet, despite entrepreneurship's important contributions to MNEs, extant IB theories often ignore this role in enterprise evolution and especially in their discussions of DCs (Al-Aali \& Teece, 2014).

Exploiting existing competences is another prerequisite for making DCs actionable. MNEs have considerable advantages when it comes to developing DCs (Teece, 2014). They typically have the slack resources needed to explore different ways to build these capabilities. In turn, entrepreneurial activities capitalize on the knowledge that MNEs gain from undertaking exploratory activities to conceive new strategies and business models and concepts. MNEs also maintain strong R\&D and 
innovation centers (often around the globe); their work could provide a foundation for conceiving novel and innovative ways of how opportunities are sensed and seized, resources allocated, and enterprise processes reconfigured. These innovation centers are often connected to MNEs' production, marketing and other operational groups that could further help in articulating the need for particular types of DCs and how to build them.

Further, many MNEs are organized as networks of federated subsidiaries that pursue different goals in different markets in different world regions (Bartlett \& Ghoshal, 1989). Some subsidiaries develop DCs of their own, employing them in the pursuit of their own goals. Some of these capabilities prove their utility beyond subsidiaries' operations and are diffused to the rest of the organization. Parent MNEs themselves develop DCs, which are then diffused throughout their subsidiaries. Researchers have yet to examine how these processes unfold or how they affect the composition of MNEs' portfolios of DCs - an issue that merits careful study.

A key challenge centers on linking MNEs' strategy, organization, DCs and entrepreneurship. Specifically, although MNEs have many advantages when it comes to infusing entrepreneurship into the development and deployment of their DCs, they also face serious challenges (Mahnke et al., 2007). For instance, the link between entrepreneurship and DCs is not automatic; MNEs' senior executives - often aided by middle managers have to find ways to activate this link by setting strategic priorities. They also need to allocate needed resources for exploring different alternatives. In turn, this sets the stage for discussions about the specific DCs their firms need. It is well established that inertia may stifle the experimentation necessary to re-conceptualize how MNEs compete and how to best assemble an effective portfolio of DCs. Here, efforts to build new capabilities may follow existing trajectories, depriving MNEs from pursuing opportunities that may lie outside of their immediate knowledge domain.

Making DCs actionable also demands having entrepreneurial top-management teams leading MNEs to build and sustain these capabilities (AlAali \& Teece, 2014; Augier \& Teece, 2007; Teece, 2016). Teece (2014) observes that DCs encompass the non-routine actions of entrepreneurial managers and the creative output of a firm's expert talent. These capabilities are deeply embedded in the routines and processes that are rooted in a firm's unique history or its heritage assets (Teece, 2014). Clearly, Teece and colleagues recognize the need for entrepreneurship as an integral part of senior executives' role in MNEs (Augier \& Teece, 2007). However, this role goes well beyond making the resource allocations and investments needed to build DCs; it also includes giving attention to the underlying organizational processes and systems that make these capabilities current, strategically focused, actionable and productive. Still, this view does not go far enough to consider the various organizational activities needed to conceive, develop and sustain these capabilities. It also overlooks the challenges MNEs and their executives encounter in aligning DCs with their firms' business models; this oversight might have contributed to the proliferation of articles aiming to explicate the nature and domain of DCs and their role while failing to explore ways to make these capabilities actionable.

The concept of "dynamic managerial capabilities" (DMC) is one attempt to make DCs actionable. Helfat and Martin (2015) define DMC as those that managers use to create, extend, and modify the ways by which their firms make a living. Adner and Helfat (2003) also proffer that managers use DMC to build, integrate and reconfigure organizational resources and competencies. Rooted in managers' human capital, cognitions and social capital, DMC induce changes in MNEs' dynamic capability sets. As such, they are a key source of strategic change that ensures evolutionary fit and successful adaptation. In turn, DMC benefit from MNEs' organizational capabilities that integrate and deploy them effectively, making them actionable. Having these capabilities is an important achievement; however, unless they are coordinated and effectively deployed, they are unlikely to give MNEs the desired advantages.

To summarize, limited research exists today on how MNEs make their DCs actionable. Our preceding discussion highlights the crucial importance of entrepreneurship in making this possible, becoming an integral part of MNEs' culture. Our discussion also illustrates the importance of DMC for MNEs' success.

\section{Entrepreneurial Actions for International New Ventures (INVs)}

INVs include born global (companies that are international at inception) and early internationalizers (companies that internationalize in the early 
years of their existence). Some of them are created and sponsored by MNEs, while others are created by individual entrepreneurs. As noted, research on DCs in new ventures has been limited; this is particularly true with INVs - those companies that internationalize their operations from inception or soon thereafter (Zahra et al., 2006; Zahra, Ireland, \& Hitt, 2000). The limited empirical research that exists on the topic suggests that INVs might benefit from having and employing DCs. For example, Monferrer, Blesa, and Ripollés (2015) using data from 303 Spanish 'born global' companies, find that marketing orientation influences these firms' two exploratory DCs (adaptation and knowledge absorption, each measured using three survey items). These capabilities in turn influenced these firm's exploitative dynamic capability (captured as innovation, measured using a five-item survey index), affecting their performance. Further, $\mathrm{Wu}$ (2007), using data from 244 Taiwanese information technology firms, found that DCs mediated the entrepreneurial resources-company performance relationship. Wu captured three dimensions of DCs: resource integration, learning and ability to adapt; he used answers to four questions in addition to four semantic differential scale responses. $\mathrm{Wu}$ 's findings support the proposition that DCs are important for the survival and growth of INVs (Sapienza et al., 2006). Some of these benefits might arise from transforming INVs' EO into actions centered on developing and exploiting DCs.

Some research suggests that INVs might have important and distinct advantages when it comes to developing DCs (Sapienza et al., 2006; Zahra, 2005). Founders usually lead these organizations, which often gives them the incentive and power (ability) to explore where and how to develop the DCs needed for survival and growth. As Al-Aali and Teece (2014: 108) state, "In INVs, sensing, seizing, and transforming may rest primarily on the shoulders of the founders. It takes time for the culture and routines that can support dynamic capabilities more broadly to become embedded throughout the organization." Relatedly, Andersson and Evers (2015) present a conceptual framework that highlights three sets of interrelated DCs: managerial cognition, social capital and networking, and human capital and learning positing that, individually and in combination, these capabilities enhance INVs' international opportunity identification, which in turn leads to international growth. Their discussion suggests that INVs' capabilities often reside in founders (and founding teams); reinforcing the importance of DMCs for INVs' growth. Given the profound role of founders (especially their dynamic managerial capabilities), Sapienza et al. (2006) propose that INVs' early commitment to international markets coincides with their development of key DCs leading to significant imprinting effect. Sapienza et al. (2006) further theorize that this imprinting effect may influence INVs' growth and survival, depending on the size and level of organizational commitments made in the pursuit of internationalization. These effects can be enduring (Prashantham \& Floyd, 2012).

Due to their relative newness, INVs do not usually suffer significant inertia that usually slows down or limits adaptation. INVs' organic structures also enable their sharing of knowledge and experience which, in turn, facilitates learning, giving them advantages over others (Prashantham \& Floyd, 2012). This learning facilitates the flow of knowledge that ensures the dynamism and currency of INVs' dynamic capabilities by making their evolution and adaptation possible. Further, INVs do not have serious irreversible commitments that limit their exploratory activities needed to conceive and develop such capabilities. INVs often escape path dependencies and have greater freedoms in development of DCs and paths for their deployment. INVs' ability to quickly put DCs to use in their operations gives them a valuable source of feedback useful in retaining their focused deployment of resource bundles on the pursuit of their goals. Finally, INVs enjoy strong EO, exhibiting high levels of innovation, risk taking and proactiveness. In a longitudinal sample of 226 Norwegian small and medium sized enterprises (SME), Madsen (2012) used survey data to examine four DCs: flexibility (seven items), opportunity search (three items), strategic assessment (three items) and learning (three items). He found that $\mathrm{EO}$ is the main factor that drives the development of the different types of DCs, controlling for type of industry and different types of resources. INVs might benefit in this fashion from having strong $\mathrm{EO}$, especially because of the presence of founders in their leadership. This presence makes it easier to transform EO into organizational decisions (e.g., resource allocations), systems (e.g., analyzing opportunities in foreign markets) and processes (e.g., building international network) to create value through internationalization.

Despite the potential benefits we have just discussed, developing DCs and making them 
actionable, can pose serious challenges for INVs. For instance, the organizational processes involved require considerable experimentation since recipes for successful DCs are not known beforehand. Though experimentation facilitates knowledge acquisition and consideration of different creative options, it raises the risk of failure. It is also costly, which may raise the cost of operations for the often financially strapped INVs, potentially inducing risk aversion into their decision-making processes.

Given the paucity of the existing empirical research on DCs in INVs, there are important issues to explore conceptually and empirically in future research. For instance, typically, INVs usually lack strong capabilities, and when they do, their capabilities are few and are lopsided (i.e., they build strong capabilities in one or few areas to the exclusion of others). This is not surprising given that capabilities in general, and DCs in particular, are costly as well as time and energy consuming to develop. While it appears logical to assume that INVs are likely to have fewer and probably different capabilities from established and resource rich MNEs, the literature does not document such differences or their implications for performance, survival and growth. Further, despite the importance of DCs for INVs' survival, profitability and growth, fundamental questions related to where they develop these capabilities and how to best keep them effectively deployed and current have not been satisfactorily addressed in the literature.

Further, INVs are unique in their missions from other companies (even domestic new ventures) as they cross international borders from inception or soon after their birth. Therefore, it would be logical to ask: Are there DCs that are unique for INVs relative to other new ventures? Some INVs are sponsored by well-healed corporations that also have long track records of internationalization. Others are founded and led by individual entrepreneurs with more limited resources and international experience. This raises a question about the implications of the imprinting processes noted by Sapienza et al. (2006); how do they differ across these two types of INVs and to what effect on growth and survival? What are the implications of this imprinting on the types of DCs used and how different INVs make these capabilities actionable?

Further, some INVs pursue purely traditional financial goals; i.e., profit seeking. Others may have social missions (Zahra, Rawhouser, Bhawe,
Neubaum, \& Hayton, 2008). Still, other INVs may pursue hybrid missions. This suggests another question: How do these variations in mission influence the DCs of these different INV types? Perhaps these different INV types develop a common set of DCs and then have distinct other capabilities. In this way, their overall portfolios of DCs may be different, with distinct implications for INVs' survival, performance and evolution. For example, social ventures expanding their operations outside their domestic markets are likely to need DCs to adapt their set of skills as they expand geographically, exploiting current assets and resources. They may need also to augment their ability to work with institutions in their different host countries. In contrast, for born global social ventures, they need DCs centered on exploration and knowledge absorption as well as those related to managing their institutional environment.

Finally, if there are such differences in the DCs across different INV types, the processes employed to develop these capabilities need documentation. Do these different INVs follow different processes in developing their DCs? Given differences in their resources, missions and especially their managerial characteristics, it would be reasonable to expect different INVs to follow different processes and paths in this regard. Currently, we do not know if and where these differences might lie or where they matter. These issues suggest a broader question: Are the underlying micro-foundations of these DCs different? Finally, how do these differences influence survival, performance and growth in international markets? Relatedly, we need to better document the contingent effects of DCs among different types of INVs, especially because the literature indicates that such benefits may vary by company size, age, mission and ownership, among others (Arend, 2012; Madsen, 2012; Sapienza et al., 2006).

An action-based view of DCs highlights the importance of agents for identifying and pursuing opportunities for achieving success. As our discussion indicates, through their actions related to building and deploying DCs, INVs can gain strategic agility that they can leverage as they deal with the challenges they encounter in foreign markets. This agility also enables them to pursue opportunities, generate necessary cash flows for operations and expansion, and grow. Their committed leadership and EO make this possible as markets change. 


\section{ADVANCING IB THEORY AND RESEARCH ON DYNAMIC CAPABILITIES}

Our preceding discussion suggests that a focus on making DCs actionable can enrich future IB theory and research in several ways while opening more avenues for future inquiry. First, the discussion draws attention to the role of deploying DCs in international markets, shaping the sources of value creation. Here, the scope, locus and use of MNEs' DCs must be carefully documented. As we have noted earlier, to date, IB researchers have not examined these issues in a systematic fashion. Importantly, focusing on DCs' deployment also highlights the potential virtuous cycle that might exist between exploratory and exploitative activities within MNEs. This cycle can promote innovation and the development of new capabilities while keeping existing DCs current. Therefore, researchers should aspire to identify the factors that influence this cycle and its implications for the evolution of DCs and how they influence firm performance.

Second, DCs' development and deployment activities often entail autonomous and induced strategic behaviors (Burgelman, 1983; Birkinshaw, 2000). Autonomous behaviors are the voluntary actions taken by MNE and subsidiaries' managers and employees to bring about entrepreneurial initiatives that promote innovation and adaptation. Induced behaviors are those sanctioned by MNEs' top management in corporate headquarters in the pursuit of formally established strategic goals. Both types of behaviors serve important goals. However, they do not always align well. Sometimes headquarter executives are slow to react to emerging IB challenges, promoting subsidiary managers to initiate actions on their own. In other cases, subsidiary managers may disagree with the mandates assigned to them by headquarters' management and may even sabotage them. This raises several questions for theory building in IB: What is the role of autonomous and induced strategic behaviors in the development and deployment of DCs? When do they complement vs. substitute each other? How do these interactions and related micro-foundations between autonomous and induced strategic behaviors unfold within and across organizational levels? To address these issues, future IB theorybuilding activities need to recognize the spatial, temporal and political dimensions of these interactions and their micro-foundations, and connect these issues to the global integration-local responsiveness framework (Birkinshaw, Morrison, \& Hulland, 1995; Prahalad \& Doz, 1987).

Third, the deployment of DCs highlights another set of questions that IB researchers need to consider: What are the different activities and processes associated with this deployment? Why do firms differ in their ability to deploy their DCs across their international markets? Do these differences stem from prior experiences? Do they reflect differences in managerial skills? Alternatively, do they arise from the complexities associated with deployment activities themselves? What is the role of the IB context in this regard?

Fourth, a focus on DCs' deployment could stimulate entrepreneurial activities with firms operating internationally. These companies need to find new ways to ensure the rapid and effective deployment of their DCs. Towards this end, future researchers can probe when and how the focus on deployment stimulates entrepreneurial activities and what types of entrepreneurial activities ensue from deployment. It is also essential to uncover how MNEs (as well as INVs) leverage their entrepreneurial activities in upgrading their DCs to ensure their potency and currency in pursuit of their overall strategic goals. In more general terms, thinking about the role of deployment of DCs in stimulating global success highlights the role of knowledge integration within the MNE. Knowledge integration is one of the key sources of MNEs' competitive advantage (Kogut \& Zander, 1992). IB researchers can extend this view by looking at the process and players for this integration and how knowledge integration leads to the creation of new DCs and how it affects the future deployment of existing capabilities.

Several researchers (e.g., Madsen, 2012) have suggested that INVs' EO makes a considerable difference in their ability to build, hone and deploy their DCs and generate advantage in their markets. However, in their meta-analysis of 101 academic papers in a variety of journals, Bitencourt, de Oliveira, Santini, Ladeira, Santos, and Teixeira (2020) find that entrepreneurial orientation (EO) was not a significant mediator of the relationship between DCs and firm performance. Yet, they found that resources, knowledge management, alliances, and environmental dynamism were all significant mediators. This has led Bitencourt et al. (2020) to reason that several factors might attenuate the role of EO as a mediator of the relationship between DCs and performance. They also suggested that market entry timing and stage of market 
development may affect the value of EO. Still, these findings invite speculations regarding the merits of $\mathrm{EO}$ in this context. It appears that what really matters are the entrepreneurial actions that transform EO into organizational activities, indicating a need to study the micro- foundations of DCs.

Fifth, most existing research on DCs examines strategic adaptation in rapidly changing markets and their effects thereof on firm performance. This is understandable given the investments made in developing and maintaining these capabilities, which are critical for successful adaptation at times of volatility and turbulence. Still, a focus on performance as the primary outcome of DCs may limit our understanding of the true magnitude of their role. DCs can change the global context in which MNEs compete, influencing the benefits they derive from these capabilities. For instance, having strong DCs in managing institutions could potentially help in shaping MNEs' future institutional environment (Cantwell et al., 2010). Moreover, the deployment of DCs can also stimulate subsequent entrepreneurial activities that create new business concepts or even business fields that change MNEs' business definition and scope of operations.

Sixth, it is clear that the role of contexts (internal and external) should be considered in designing future research studies. Indeed, Lessard, Teece and Heaton (2016b) observe that existing research findings may lack relevance because they ignore the context in which DCs work best. Context could lead firms to develop particular capabilities. It could also cause the decay of these capabilities. Context also could moderate the effect of DCs on organizational outcomes. The forms of this effect (independent, moderation and mediation) need to be empirically documented.

Another important line of future inquiry pertains to how geography, location, culture, institutions or history may affect the set of DCs that MNEs have. While each of these variables could have its distinct effects, their interactions could have even more profound effects on the underlying structure of the DC construct. These interactions are likely to be dynamic, necessitating consideration of temporal implications of the content and effects of DCs and more sophisticated empirical designs. Does IB context reveal or require additional capacities for MNEs' effective development and deployment of DCs, beyond the familiar sensing, seizing, and transforming?
Seventh, we see abundant opportunities to integrate DC thinking with existing IB theories and perspectives, particularly with the 'new' internalization theory which emphasizes the shifts towards the recombination or bundling of existing FSAs with country-specific advantages (CSAs) available in host countries (Hennart, 2009; Verbeke, 2009). It also complements the integration-responsiveness balance perspective (Birkinshaw et al., 1995; Prahalad \& Doz, 1987) in the sense that DC building and deployment is performed through simultaneously meeting both global mandate demand and local mandate demand. DC thinking may enrich the knowledge-based view of MNEs as well (Kogut \& Zander, 1992) to the extent that the latter's insights about knowledge type, knowledge transferability, knowledge combination, and reconfiguration of internal and external resources provide additional yet complementary accounts for DCs' development. Future research should delineate the boundary conditions under which the above complementarity unfolds.

Eight, DC thinking also captures adaptive learning. A nuanced understanding of the actionable processes and mechanisms underlying this learning is paramount for IB research. MNEs need to engage in adaptive learning under conditions of environmental instability and complexity in their multiple industries and markets (Luo \& Peng, 1999). Both DC thinking and adaptive learning logic (Levinthal, 1997) articulate a dynamic process of organizational adaptation to address rapidly changing and complex environments. It merits renewed attention to how MNEs, young and established, capitalize on their learning and experience in defining and developing their future DCs.

Similarly, successfully exploiting DCs requires strong organizational support. A specific question in this regard is learning mindfulness. This mindfulness is a state of active awareness characterized by the continual creation and refinement of categories, an openness to new information, and a willingness to view contexts from multiple perspectives (Levinthal \& Rerup, 2006). Such mindfulness mirrors a firm's ability to effectively undertake novel action in a flexible manner, and to maintain and sustain a high level of attention and sensitivity to errors and unexpected events, whereas lessmindful behavior resonates more with a firm's routine/rule-driven behavior (Levinthal \& Rerup, 2006). Learning mindfulness can serve as a foundation for establishing and leveraging DCs, and can be a key element of an MNE's organizational 
support for building and upgrading capabilities to address constantly shifting parameters in IB contexts.

The premise of much of DCs research in general, and for IB in particular, is on achieving novel resource recombinations that demand effective and flexible resource reallocation. Yet, this comes at a cost. Specifically, Winter (2003: 993) warns that "attempting too much change - perhaps in a deliberate effort to exercise the dynamic capability - can impose additional costs when the frequent disruption of the underlying capability outweighs the competitive value of the novelty achieved". As firms operating in international markets experience increased levels of disruptions and volatility in their external environments, the internal disruptions with the goal of developing upgraded capabilities can often pose significant challenges and costs that should be also acknowledged and incorporated in future research.

\section{CONCLUSIONS AND FINDINGS FROM THIS SPECIAL ISSUE}

This Special Issue attracted submissions that sought to develop an actionable agenda for the DC perspective in IB, theoretically and empirically aiming to contribute to the study of cross-national business activities in a complex global context. The papers accepted in this Special Issue highlight some important aspects of making DCs actionable for and in IB to effectively respond to internal and external pressures and competing mandates when operating in international markets. They also highlight the diversity of empirical methods that can accommodate the complexity of the DC construct. Specifically, the paper by Arikan, Koparan, Arikan and Shenkar (forthcoming) entitled "Dynamic capabilities and internationalization of authentic firms: Role of heritage assets, administrative heritage and signature processes" addresses two tensions (internal and external) that MNEs with strong signature processes and administrative heritage encounter when operating in international markets. Their case study of five Italian firms shows that these companies achieve evolutionary fitness with their external environment by intentionally enacting scanning, buffering, and preserving of their signature processes and administrative heritage rather than focusing on change associated with sensing, seizing and reconfiguration capacities. These findings are counterintuitive to the traditional focus on change and adaptation that dynamic capability thinking implies. Instead, for these firms, adaptation is wrapped around the staying power of their heritage endowments and signature processes. In addition to the dynamics of search and change, reconfiguration and rebalancing, that are traditionally associated with DCs, this article explains the role of scanning, buffering, and preserving of heritage endowments in achieving competitive advantage. By doing so, this article highlights the importance of idiosyncratic, signature processes and the importance of protecting and preserving those in the face of growing global competition (Teece, 2014). While Teece (2007), in his seminal work, identified the need for both sensing of threats and neutralizing them, much of the literature since then has focused on seizing of sensed opportunities and how to reconfigure the organization to act upon those. Arikan's et al. (forthcoming) paper specifically zooms in on this less studied aspect of DCs. The focus on scanning for potential threats and buffering and preserving signature processes and heritage endowments become especially critical for MNEs operating in institutionally weak environments (Lundan \& Li, 2019) and when proprietary knowledge and IP is subject to misappropriation hazards (Petricevic \& Teece, 2019). This article also reveals that these firms pursue internationalization paths that are different from those that the traditional IB literature would suggest. Specifically, these firms pursue internationalization only if it allows them to preserve their heritage endowments. By doing so, they intentionally resist adaptation and instead leverage their location-bound FSAs.

In sharp contrast with the paper by Arikan et al. (forthcoming) that stresses stability rather than dynamism in the firm's capabilities for achieving evolutionary fitness, the study by Grogaard, Colman, and Stensaker (forthcoming) entitled "Legitimizing, leveraging, and launching: Developing dynamic capabilities in the MNE" identifies mechanisms that mobilize and power the recombination conduits of DCs in MNEs. Through a longitudinal case study analysis that spans 12 years of a Nordic multinational, the authors identify legitimizing, leveraging and launching as important clusters of capacities underpinning DCs in MNEs. Specifically, they identify legitimizing of strategic change, leveraging of organizational strengths (which also include signature processes and heritage endowments identified by Arikan et al.), and launching of new initiatives as three pillars of the resource recombination process. Thus, the study highlights the recursive nature of DC development in MNEs, 
and also reveals the plurality of processes and paths that characterize DCs (Teece et al., 1997). Their study further reveals that sensing, seizing and reconfiguring are not a straightforward and uncontested processes. Instead, it observes some of the dynamics embedded in a self-regulating system of interdependent relationships (Teece, 2018) and the critical role of learning in the evolution of DCs (Zollo \& Winter, 2002).

Diving even deeper inside the "black box" of organizational processes that foster reconfiguration capacities, the paper by Distel and colleagues (forthcoming) entitled "Dynamic capabilities for hire - how former host country entrepreneurs as MNC subsidiary managers affect performance" identifies the significant impact of hiring entrepreneurial talent on enhancing DCs in MNE's subsidiaries, much in line with Teece's $(2012,2016)$ observation that entrepreneurship is a key mechanism that fosters DCs. Using longitudinal employer-employee data of 5587 MNE subsidiaries in Portugal, Distel and colleagues show that hiring host country entrepreneurs as subsidiary managers enhances resource reconfigurations and leads to stronger performance effects. The authors also identify actionable approaches to infuse entrepreneurship through intentionally designed hiring practices when managing the internationally dispersed networks of subsidiaries.

In a similar vein and by focusing on the microfoundations, the paper by Tasheva and Nielsen (forthcoming) entitled "The role of global dynamic managerial capability in the pursuit of international strategy and superior performance" explicate the global dynamic managerial capability (GDMC) as a unique set of three micro-foundational capacities that help managers navigate diverse institutional environments: international human capital, international social capital, and international managerial cognitions. Analyzing data on executive characteristics and team compositions from 165 Swiss publicly listed firms, the authors show that GDMC enhances the ability of firms to select and implement appropriate strategies for international activities. In particular, they show how GDMC at the team level can influence deployment of firmlevel DCs - namely global asset orchestration leading to improved firm's performance. Their study underscores the critical role that managers play in developing and deploying MNE's DCs (Augier \& Teece, 2009) and the importance of integrating macro-context and micro-foundations in developing actionable insights of applying DCs framework for IB (Coviello, Kano, \& Liesch, 2017).

While the four papers discussed above primarily focused on identifying specific internal processes or clusters of capacities underpinning DCs of MNEs, the paper by Zhang, Xie, Li and Cheng, (forthcoming) entitled "'Outside in': Global demand heterogeneity and dynamic capabilities of multinational enterprises" explores how the global demand heterogeneity in MNE's external (international) environment impacts the development of such capabilities. By studying Chinese service firms, the authors identify the significant impact of the demand environment on the use of DCs (in terms of requisite innovation and strategic flexibility). Findings support the observation that the context in which MNEs operate significantly influences their ability to achieve evolutionary fitness (Helfat et al., 2007) and that greater attention should be paid to examining the external conditions (e.g., customer preferences) that may impose different requirements on the processes and resource bundles necessary for development and deployment of DCs in IB.

Similar to Zhang et al., the paper by Maksimov, Wang and Yan (forthcoming) entitled "Global connectedness and dynamic green capabilities in MNEs" identifies how the increasing pressures for achieving environmental sustainability as one form of evolutionary fitness impacts the deployment of a particular type of a dynamic capability, namely a "green" DC. Contrary to the non-sequential nature of mobilizing reconfiguration capacities in MNEs identified by Grøgaard and her colleagues, the study by Maksimov et al. suggests that development of sensing-seizing-reconfiguring capacities in the context of environmental sustainability follows a more sequential nature. This further solidifies the notion that context plays a critical role in identifying the relevant processes and paths of resource orchestration required for developing and deploying of DCs.

While the articles in this Special Issue clearly show that DCs reflect an inherently complex, multi-dimensional construct (Winter, 2003), they also help to demystify DCs for scholars and managers in IB. Specifically, the papers identify additional dimensions of DCs in MNEs (e.g., scanning, buffering, protecting - Arikan et al. or legitimizing, leveraging, launching - Grogaard et al.) that are finer-grained and go beyond traditionally conceptualized sensing, seizing and reconfiguring capacities (Teece, 2007). Thus, the papers also highlight 
the need to carefully balance orchestration and alignment of resources bundles and FSAs in MNEs. By observing the critical role of entrepreneurial thinking and action as an important mechanism for the emergence and enhancement of DCs, Distel et al. identify one approach for enhancing orchestration and reconfiguration activities in MNEs. By employing latent growth modeling, Tasheva and Nielsen advance the application of DMCs for the IB context. Finally, the papers by Zhang et al. and Makismov et al. specify external contingencies (i.e., additional competing mandates) that guide and

\section{REFERENCES}

Adner, R., \& Helfat, C. E. 2003. Corporate effects and dynamic managerial capabilities. Strategic Management Journal, 24(10): 1011-1025.

Al-Aali, A., \& Teece, D. J. 2014. International entrepreneurship and the theory of the (long-lived) international firm: A capabilities perspective. Entrepreneurship Theory and Practice, 38(1): 95-116.

Andersson, S., \& Evers, N. 2015. International opportunity recognition in international new ventures-a dynamic managerial capabilities perspective. Journal of International Entrepreneurship, 13(3): 260-276.

Arend, R. J. 2012. Entrepreneurship and dynamic capabilities: How firm age and size affect the 'capability enhancementSME performance' relationship. Small Business Economics, 42(1): 33-57.

Arikan, I. T., Koparan, I., Arikan, A. M., \& Shenkar, O. forthcoming. Dynamic capabilities and internationalization of authentic firms: Role of heritage assets, administrative heritage and signature processes. Journal of International Business Studies.

Augier, M., \& Teece, D. J. 2007. Dynamic capabilities and multinational enterprise: Penrosean insights and omissions. Management International Review, 47(2): 175-192.

Augier, M., \& Teece, D. J. 2009. Dynamic capabilities and the role of managers in business strategy and economic performance. Organization Science, 20(2): 410-421.

Banalieva, E., \& Dhanaraj, C. 2019. Internalization theory for the digital economy. Journal of International Business Studies (in press).

Barney, J. 1991. Firm resources and sustained competitive advantage. Journal of Management, 17(1): 99-120.

Bartlett, C. A., \& Ghoshal, S. 1989. Managing across boarders. Harvard Business School Press.

Birkinshaw, J. 2000. Entrepreneurship in the global firm. SAGE.

Birkinshaw, J., Morrison, A., \& Hulland, J. 1995. Structural and competitive determinants of a global integration strategy. Strategic Management Journal, 16(8): 637-655.

Bitencourt, C. C., de Oliveira Santini, F., Ladeira, W. J., Santos, A. C., \& Teixeira, E. K. 2020. The extended dynamic capabilities model: A meta-analysis. European Management Journal, 38(1): 108-120.

Burgelman, R. A. 1983. Corporate entrepreneurship and strategic management: Insights from a process study. Organization Science, 29(12): 1349-1455.

Cantwell, J., Dunning, J. H., \& Lundan, S. M. 2010. An evolutionary approach to understanding international business activity: The co-evolution of MNEs and the institutional environment. Journal of International Business Studies, 41(4): 567-586.

Cheng, J., Birkinshaw, J., Lessard, D., \& Thomas, D. 2014. Advancing interdisciplinary research in international business: impact the direction of renewal and upgrading of MNEs' DCs to continuously achieve evolutionary fitness in increasingly flux international markets. Thus, besides improving our understanding of DCs' role in today's international marketplace, these articles also highlight an interesting set of issues and methodological diversity worthy of exploration in future IB research. We hope these articles and the ideas they offer will stimulate research on the nature and role of DCs in MNEs and INVs and how to make these capabilities actionable.

Integrative knowledge and transformative theories. Journal of International Business Studies, 45(6): 643-648.

Coviello, N., Kano, L., \& Liesch, P. W. 2017. Adapting the Uppsala model to a modern world: Macro-context and microfoundations. Journal of International Business Studies, 48(9): 1151-1164.

Cui, Y., \& Jiao, H. 2011. Dynamic capabilities, strategic stakeholder alliances and sustainable competitive advantage: evidence from China. Corporate Governance, 11(4): 386-398.

Deng, P., Liu, Y., Gallagher, V., \& Wu, X. 2020. International strategies of emerging market multinationals: A dynamic capabilities perspective. Journal of Management and Organization, 26(4): 408-425.

Distel, A., Sofka, W., de Faria, P., Preto, M.T., \& Ribeiro, A. forthcoming. Dynamic capabilities for Hire-how former host country entrepreneurs as MNC subsidiary managers affect performance. Journal of International Business Studies.

Dunning, J. H., \& Lundan, S. M. 2010. The institutional origins of dynamic capabilities in multinational enterprise. Industrial and Corporate Change, 19(4): 1225-1246.

Fang, E. E., \& Zou, S. 2009. Antecedents and consequences of marketing dynamic capabilities in international joint ventures. Journal of International Business Studies, 40(5): 742-761.

Grøgaard, B. Colman, H. L., \& Stensaker, I. G. forthcoming. Legitimizing, leveraging, and launching: Developing dynamic capabilities in the MNE. Journal of International Business Studies.

Helfat, C., Finkelstein, S., Mitchell, W., Peteraf, M., Singh, H., Teece, D., \& Winter, S. 2007. Dynamic capabilities: Understanding strategic change in organisations. Blackwell Publishing.

Helfat, C. E., \& Martin, J. A. 2015. Dynamic managerial capabilities: Review and assessment of managerial impact on strategic change. Journal of Management, 41(5): 1281-1312.

Hennart, J. F. 1982. A theory of multinational enterprise. University of Michigan Press.

Hennart, J. F. 2009. Down with MNE-centric theories! Market entry and expansion as the bundling of MNE and local assets. Journal of International Business Studies, 40(9): 1432-1454.

Hutzschenreuter, T., Pedersen, T., \& Volberda, H. W. 2007. The role of path dependency and managerial intentionality: A perspective on international business research. Journal of International Business Studies, 38(7): 1055-1068.

Inkpen, A., Minbaeva, D., \& Tsang, E. W. 2019. Unintentional, unavoidable, and beneficial knowledge leakage from the multinational enterprise. Journal of International Business Studies, 50(2): 250-260.

lansiti, M., \& Clark, K. B. 1994. Integration and dynamic capability: Evidence from product development in automobiles and mainframe computers. Industrial and Corporate Change, 3(3): 557-605. 
Kano, L. 2018. Global value chain governance: A relational perspective. Journal of International Business Studies, 49(6): 684-705.

Kogut, B., \& Zander, U. 1992. Knowledge of the firm, combinative capabilities, and the replication of technology. Organization Science, 3(2): 383-397.

Kostova, T., Marano, V., \& Tallman, S. 2016. Headquarterssubsidiary relationships in MNCs: Fifty years of evolving research. Journal of World Business, 51(1): 176-184.

Lessard, D., Teece, D. J., \& Heaton, S. 2016a. Introduction to special topic forum on developing the dynamic capabilities of global companies across levels and locations. Global Strategy Journal, 6(3): 165-167.

Lessard, D., Teece, D. J., \& Heaton, S. 2016b. Dynamic capabilities of meta-multinationals. Global Strategy Journal, 6(3): $211-224$.

Levinthal, D. 1997. Adaptation on rugged landscapes. Management Science, 43(7): 934-950.

Levinthal, D., \& Rerup, C. 2006. Crossing an apparent chasm: Bridging mindful and less-mindful perspectives on organizational learning. Organization Science, 17(4): 417-526.

Li, J., Chen, L., Yi, J., Mao, J., \& Liao, J. 2019. Ecosystem-specific advantages in international digital commerce. Journal of International Business Studies, (forthcoming).

Lundan, S. M., \& Li, J. 2019. Adjusting to and learning from institutional diversity: Toward a capability-building perspective. Journal of International Business Studies, 50(1): 36-47.

Luo, Y. 2000. Dynamic capabilities in international expansion. Journal of World Business, 35(4): 355-378.

Luo, Y. 2002. Capability exploitation and building in a foreign market: Implications for multinational enterprises. Organization Science, 13(1): 48-63.

Luo, Y., \& Peng, M. 1999. Learning to compete in a transition economy: Experience, environment and Performance. Journal of International Business Studies, 30(2): 269-295.

Madhok, A., \& Osegowitsch, T. 2000. The international biotechnology industry: A dynamic capabilities perspective. Journal of International Business Studies, 31(2): 325-335.

Madsen, E. L. 2012. Entrepreneurship and dynamic capabilities-An empirical testing. International Journal of Technology, Intelligence and Planning, 8(4): 317-332.

Mahnke, V., Venzin, M., \& Zahra, S. 2007. Governing entrepreneurial opportunity recognition in MNEs: Aligning interests and cognition under uncertainty. Journal of Management Studies [special Issue], 44: 1278-1298.

Maksimov, V., Wang, S. L., \& Yan, S. forthcoming. Global connectedness and dynamic green capabilities in MNEs. Journal of International Business Studies.

Matysiak, L., Rugman, A. M., \& Bausch, A. 2018. Dynamic capabilities of multinational enterprises: The dominant logics behind sensing, seizing, and transforming matter! Management International Review, 58(2): 225-250.

Meyer, K. E., Mudambi, R., \& Narula, R. 2011. Multinational enterprises and local contexts: The opportunities and challenges of multiple embeddedness. Journal of Management Studies, 48(2): 235-252.

Monferrer, D., Blesa, A., \& Ripollés, M. 2015. Born globals trough knowledge-based dynamic capabilities and network market orientation. BRQ Business Research Quarterly, 18(1): $18-36$.

Narula, R. 2017. Emerging market MNEs as meta-integrators: The importance of internal networks. International Journal of Technology Management, 74(1-4): 214-220.

Narula, R., \& Verbeke, A. 2015. Making internalization theory good for practice: The essence of Alan Rugman's contributions to international business. Journal of World Business, 50(4): 612-622.

Pananond, P., Gereffi, G., \& Pedersen, T. 2020. An integrative typology of global strategy and global value chains: The management and organization of cross-border activities. Global Strategy Journal, 10(3): 421-443.
Parente, R. C., Baack, D. W., \& Hahn, E. D. 2011. The effect of supply chain integration, modular production, and cultural distance on new product development: A dynamic capabilities approach. Journal of International Management, 17(4): 278-290.

Peng, M. W. 2001. The resource-based view and international business. Journal of Management, 27(6): 803-829.

Petricevic, O., \& Teece, D. J. 2019. The structural reshaping of globalization: Implications for strategic sectors, profiting from innovation, and the multinational enterprise. Journal of International Business Studies, 50(9): 1487-1512.

Pitelis, C. N., \& Teece, D. J. 2010. Cross-border market cocreation, dynamic capabilities and the entrepreneurial theory of the multinational enterprise. Industrial and Corporate Change, 19(4): 1247-1270.

Pitelis, C. N., \& Teece, D. J. 2018. The new MNE: 'Orchestration' theory as envelope of 'Internalisation' theory. Management International Review, 58(4): 523-539.

Prahalad, C. K., \& Doz, Y. 1987. The multinational mission: Balancing local demands and global vision. Free Press.

Prashantham, S., \& Floyd, S. 2012. Routine microprocesses and capability learning in international new ventures. Journal of International Business Studies, 43(6): 544-562.

Regnér, P., \& Edman, J. 2014. MNE institutional advantage: How subunits shape, transpose and evade host country institutions. Journal of International Business Studies, 45(3): 275-302.

Rugman, A. M. 1981. Inside the multinationals. Croom Helm.

Rugman, A. M., \& Verbeke, A. 2001. Subsidiary-specific advantages in multinational enterprises. Strategic Management Journal, 22(3): 237-250.

Rugman, A. M., \& Verbeke, A. 2003. Extending the theory of the multinational enterprise: Internalization and strategic management perspectives. Journal of International Business Studies, 34(2): 125-137.

Rugman, A. M., Verbeke, A., \& Nguyen, Q. 2011. Fifty years of international business theory and beyond. Management International Review, 51(6): 755-786.

Sapienza, H. J., Autio, E., George, G., \& Zahra, S. 2006. Capabilities perspective on the effects of early internationalization on firm survival and growth. Academy of Management Review, 31(4): 914-933.

Tasheva, S., \& Nielsen, B. B. forthcoming. The role of global dynamic managerial capability in the pursuit of international strategy and superior performance. Journal of International Business Studies.

Teece, D. J. 2007. Explicating dynamic capabilities: The nature and microfoundations of (sustainable) enterprise performance. Strategic Management Journal, 28(13): 1319-1350.

Teece, D. J. 2012. Dynamic capabilities: Routines versus entrepreneurial action. Journal of Management Studies, 49(8): 1395-1401.

Teece, D. J. 2014. A dynamic capabilities-based entrepreneurial theory of the multinational enterprise. Journal of International Business Studies, 45(1): 8-37.

Teece, D. J. 2016. Dynamic capabilities and entrepreneurial management in large organizations: Toward a theory of the (entrepreneurial) firm. European Economic Review, 86: 202-216.

Teece, D. J. 2018. Dynamic capabilities as (workable) management systems theory. Journal of Management and Organization, 24(3): 359-368.

Teece, D. J., \& Petricevic, O. 2020. Capability-based theories of MNE growth. In K. Mellahi, K. Meyer, R. Narula, I. Surdu, \& A. Verbeke (Eds.), The oxford handbook of international business strategy. Oxford University Press.

Teece, D. J., Pisano, G., \& Shuen, A. 1997. Dynamic capabilities and strategic management. Strategic Management Journal, 18(7): 537-533.

Verbeke, A. 2009. International business strategy. Cambridge University Press. 
Verbeke, A., \& Asmussen, C. G. 2016. Global, local, or regional? The locus of MNE strategies. Journal of Management Studies, 53(6): 1051-1075.

Verbeke, A., \& Kenworthy, T. P. 2008. Multidivisional vs metanational governance of the multinational enterprise. Journal of International Business Studies, 39(6): 940-956.

Weerawardena, J., Mort, G. S., Liesch, P. W., \& Knight, G. 2007. Conceptualizing accelerated internationalization in the born global firm: A dynamic capabilities perspective. Journal of World Business, 42(3): 294-306.

Wilden, R., Devinney, T. M., \& Dowling, G. R. 2016. The architecture of dynamic capability research identifying the building blocks of a configurational approach. Academy of Management Annals, 10(1): 997-1076.

Winter, S. G. 2003. Understanding dynamic capabilities. Strategic Management Journal, 24(10): 991-995.

Witt, M. A. 2019. De-globalization: Theories, predictions, and opportunities for international business research. Journal of International Business Studies, 50(7): 1053-1077.

Wu, H., Chen, J., \& Jiao, H. 2016. Dynamic capabilities as a mediator linking international diversification and innovation performance of firms in an emerging economy. Journal of Business Research, 69(8): 2678-2686.

$\mathrm{Wu}$, L.-Y. 2007. Entrepreneurial resources, dynamic capabilities and start-up performance of Taiwan's high-tech firms. Journal of Business Research, 60(5): 549-555.

Zahra, S. A. 2005. A theory of international new ventures: A decade of research. Journal of International Business Studies, 36(1): 20-28.

Zahra, S. A. 2020. International entrepreneurship (IE) in the age of political turbulence. Academy of Management Discoveries, 6(2): 172-175

Zahra, S., Ireland, D. R., \& Hitt, M. 2000. International expansion by new venture firms: International diversity, mode of market entry, technological learning and performance. Academy of Management Journal, 43(5): 925-950.

Zahra, S., Rawhouser, H., Bhawe, N., Neubaum, D., \& Hayton, J. 2008. Globalization of social entrepreneurship opportunities. Strategic Entrepreneurship Journal, 2(2): 117-131.

Zahra, S., Sapienza, H., \& Davidsson, P. 2006. Entrepreneurship and dynamic capabilities: A review, model and research agenda. Journal of Management Studies, 43(4): 917-955.

Zeng, R., Grøgaard, B., \& Steel, P. 2018. Complements or substitutes? A meta-analysis of the role of integration mechanisms for knowledge transfer in the MNE network. Journal of World Business, 53(4): 415-432.
Zhang, X., Xie, L., Li, J., \& Cheng, L. forthcoming. "Outside in": Global demand heterogeneity and dynamic capabilities of multinational enterprises. Journal of International Business Studies.

Zollo, M., \& Winter, S. G. 2002. Deliberate learning and the evolution of dynamic capabilities. Organization Science, 13(3): 339-351.

\section{ABOUT THE AUTHORS}

Shaker A. Zahra is Robert E. Buuck Chair and Professor Strategic Management and Entrepreneurship, Carlson School of Management, University of Minnesota. His research centers on entrepreneurship in global technology and science-based industries, corporate entrepreneurship, and innovation. He is a Fellow of AOM.

Olga Petricevic (PhD, Georgia State University) is an Associate Professor at the Haskayne School of Business, University of Calgary. Her current and published work examines the nature and the role of dynamic capabilities in the context of high-technology firms and by adopting interdisciplinary perspectives. She serves on the Editorial Boards of several leading academic journals.

Yadong Luo (PhD, Temple University) is the Emery Findley Distinguished Chair and Professor of Management at University of Miami Business School. His research interests include global strategy, international management, and emerging markets. He is a Fellow of AIB and AOM.

Publisher's Note Springer Nature remains neutral with regard to jurisdictional claims in published maps and institutional affiliations.

Accepted by Alain Verbeke, Editor-in-Chief, 12 July 2021. This article has been with the authors for one revision and was single-blind reviewed. 